\section{Canonical Wnt signals are essential for homeostasis of the intestinal epithelium}

\author{
Daniel Pinto, Alex Gregorieff, Harry Begthel, and \\ Hans Clevers ${ }^{1}$
}

Netherlands Institute for Developmental Biology, Hubrecht Laboratory, Uppsalalaan 8, 3584 CT Utrecht, The Netherlands

To assess the critical role of Wnt signals in intestinal crypts, we generated transgenic mice ectopically expressing Dickkopf1 (Dkk1), a secreted Wnt inhibitor. We find that epithelial proliferation is greatly reduced coincidentally with the loss of crypts. Although enterocyte differentiation appears unaffected, secretory cell lineages are largely absent. Disrupted intestinal homeostasis is reflected by an absence of nuclear $\beta$-catenin, inhibition of c-myc expression, and subsequent up-regulation of p21 ${ }^{\text {CIP1/WAF1 }}$. Thus, our data are the first to establish a direct requirement for Wnt ligands in driving proliferation in the intestinal epithelium, and also define an unexpected role for Wnts in controlling secretory cell differentiation.

Supplemental material is available at http://www.genesdev.org.

Received April 7, 2003; revised version accepted May 16, 2003.

Activation of canonical Wnt signaling is initiated by binding of secreted Wnt glycoproteins to their transmembrane coreceptors, the Frizzled proteins $(\mathrm{Fz})$ and the LDL receptor-related proteins 5 and 6 (LRP5/6; Zorn 2001). The Wnt-Fz-LRP5/6 complex transduces a signal into the cell, resulting in nuclear accumulation of $\beta$-catenin and subsequent activation of TCF target genes. Formation of this complex is inhibited specifically and potently by the secreted protein Dickkopf1 (Dkk1; Tamai et al. 2000; Bafico et al. 2001; Mao et al. 2001; Semenov et al. 2001; Andl et al. 2002).

Previous in vivo studies implicate Wnt signals in the regulation of intestinal stem cell proliferation (Kinzler and Vogelstein 1996; Bienz and Clevers 2000; Booth et al. 2002). First, proliferative cells at the bottom of the small intestine (Batlle et al. 2002) and the colon (van de Wetering et al. 2002) crypts accumulate nuclear $\beta$-catenin. Second, mutations that activate the Wnt/ $\beta$-catenin pathway can lead to colorectal cancer in humans (Powell et al. 1992; Kinzler and Vogelstein 1996; Fodde et al. 2001) as well as adenomatous polyp formation in the mouse intestine (Moser et al. 1990; Fodde et al. 1994; Oshima et al. 1995; Shibata et al. 1997), whereas mutation of Tcf4 leads to the depletion of intestinal proliferative compartments in fetal mice (Korinek et al. 1998). Although these

[Keywords: Intestinal epithelium; canonical Wnt signaling; Dickkopf1] ${ }^{1}$ Corresponding author.

E-MAIL clevers@niob.knaw.nl; FAX 31-30-2121801.

Article and publication are at http://www.genesdev.org/cgi/doi/10.1101/ gad.267103. studies address the function of downstream components of the Wnt/ $\beta$-catenin pathway, they do not provide evidence for the requirement of Wnt signals themselves in the regulation of intestinal proliferation.

Our initial studies indicated that at least four Wnt genes (i.e., Wnt4, Wnt6, Wnt11, and Wnt14b; D. Pinto, A. Gregorieff, and H. Clevers, unpubl.) were expressed specifically in crypts of embryonic and adult small intestine. Potential redundancy precluded a direct analysis of the role of these Wnt genes in crypt biology. We therefore adopted a strategy to block all Wnt-Fz-LRP5/6 interactions by targeting expression of the Dkk1 inhibitor to the proliferative compartments of the mouse intestine. We generated transgenic mouse lines expressing the murine Dkk1 cDNA under the control of a 9-kb regulatory region of the mouse villin gene, which has previously been shown to direct transgene expression specifically and efficiently to the epithelial layer of the entire intestinal crypt-villus unit (Pinto et al. 1999; Janssen et al. 2002).

\section{Results and Discussion}

Three transgenic founders were obtained. Transgene expression was readily detected in the intestines of all animals tested (see Supplementary Fig. 1). No gross morphological changes were observed upon histological analysis of the intestinal epithelia of hemizygous $F_{1}$ mice. Yet Paneth cells were aberrantly allocated in the small intestine of all three transgenic lines (see Supplementary Fig. 2A,B). This observation was reminiscent of the recent finding of our laboratory that the $\beta$-catenin downstream target gene EphB3 is required for the correct allocation of Paneth cells to the bottom of the crypts (Batlle et al. 2002). This prompted us to verify whether Dkk1 expression was affecting Paneth cell allocation through control of Eph expression. Immunohistochemical analysis of lysozyme (a Paneth cell marker) and EphB3 expression performed on serial sections of the small intestine from transgenic adult animals revealed that the mispositioned Paneth cells in the midpart of the crypt were devoid of EphB3 staining. In contrast, Paneth cells located at normal positions at the crypt base were EphB3-positive (see Supplementary Fig. 2C,D). These observations provided formal proof that Paneth cell positioning in the normal adult intestinal epithelium is tightly regulated by canonical Wnt signaling, and for the consequent control over EphB3 expression. Because lysozyme expression was unaffected by Dkk1 transgene expression, our findings also demonstrate in vivo selective regulation by Wnts of a $\beta$-catenin/Tcf 4 downstream target gene (i.e., EphB3) in a terminally differentiated epithelial cell type, namely, in Paneth cells.

To increase expression of the transgene, we next generated homozygous $\mathrm{F}_{2}$ mice. Wild-type and homozygous littermates were killed at adult stages (1-3 mo) to ensure analysis of mature intestines exhibiting a definitive crypt-villus architecture (achieved in the mouse by postnatal day 28; Gordon and Hermiston 1994). At low magnification, sections of small intestines from Dkk1 homozygous transgenic mice revealed a disorganized and unpacked mucosa with shortened villi that were significantly decreased in number compared with nontransgenic samples (Fig. 1A,B). At higher magnification, 

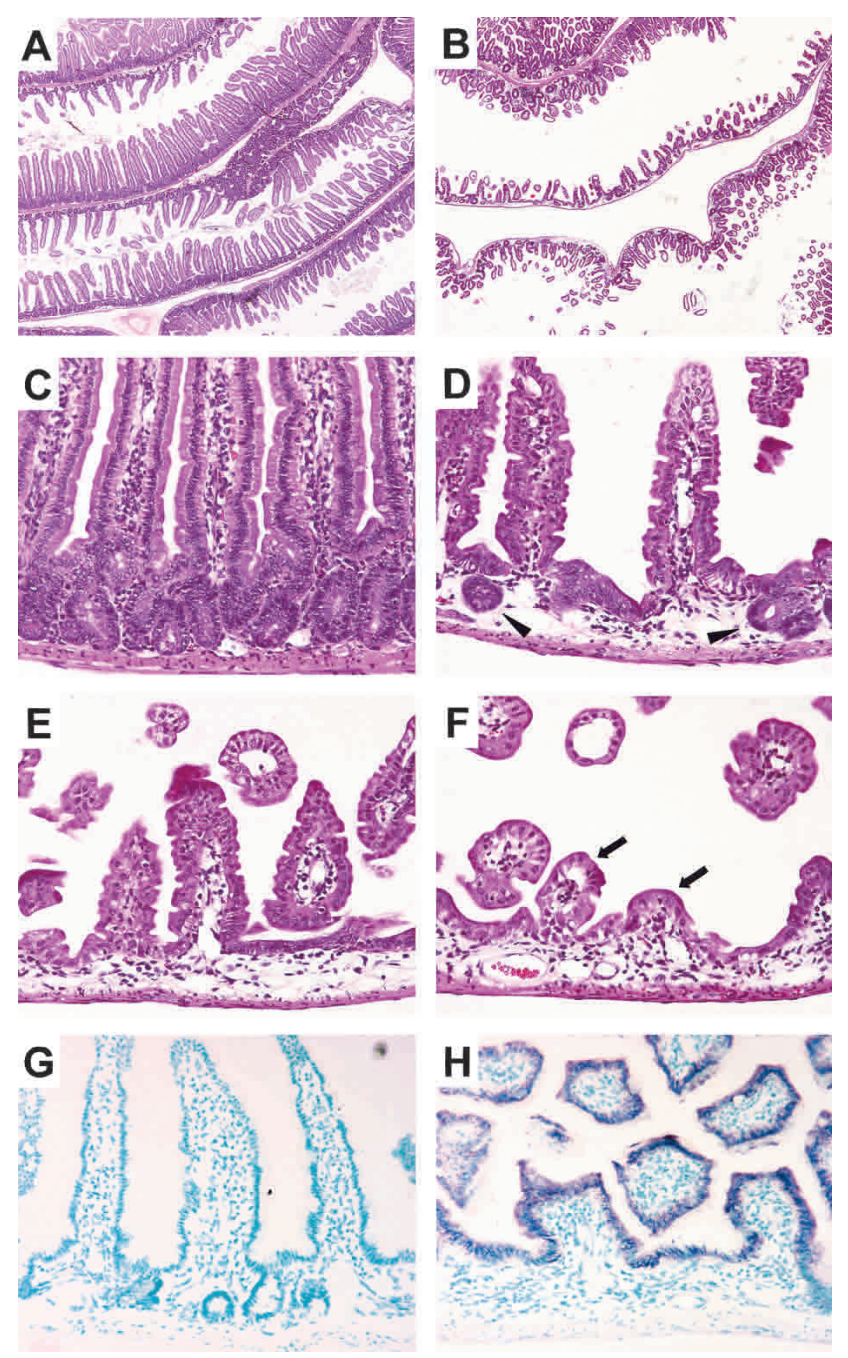

Figure 1. Dkk1 ectopic expression deleteriously affects crypt-villus organization. Representative sections of the small intestine from wild-type $(A, C)$ and transgenic $(B, D-F)$ adult animals stained with hematoxylin/eosin. The number and the size of crypts and villi are drastically reduced in the transgenic mucosa to rare residual cryptlike structures (arrowheads in $D$ ) or few residual villi (arrows in $F$ ). In situ hybridization analysis of small intestine sections from wildtype $(G)$ and transgenic $(H)$ mice hybridized with a Dkk1 antisense RNA probe. Note that Dkk1 is only expressed in the transgenic epithelium. Original magnification: $A, B, 2 \times ; C-H, 20 \times$.

whereas wild-type crypts and villi were seen to alternate with strict regularity (Fig. 1C), the villi in transgenic animals appeared shorter and the crypts were drastically reduced in size and number to a few residual structures (Fig. 1D). Regionally, the epithelium of transgenic mice displayed stronger phenotypes with no apparent crypts (Fig. 1E) and very few residual villi (Fig. 1F). No obvious alteration in submucosal and muscular layers could be observed. In situ hybridization revealed that transgene expression was restricted to the epithelial layer of the small intestine and coincided with regions of crypt loss in transgenic mice, whereas no expression was detected in wild-type littermates (Fig. 1G,H), as expected. Taken together, these findings showed that ectopic expression of Dkk1 induces morphological alteration of the intestinal epithelium by affecting crypt integrity.
The absence of crypts suggested that proliferation could be perturbed in the small intestine of Dkk1 transgenic mice. We assessed the proliferative status of the transgenic mucosa by performing immunohistochemistry for the nuclear proliferation marker Ki-67 (Schluter et al. 1993). In the wild-type epithelium, proliferative cells were distributed regularly and uniformly in every crypt (Fig. 2A,C). In contrast, patches of Ki-67-positive crypts were scattered throughout the transgenic epithelium with frequent and large unstained areas corresponding to regions lacking crypts, except for some rare positive cells in a few residual crypts (Fig. 2B,D). These observations were confirmed by analysis of 5-bromo-2-deoxyuridine (BrdU) incorporation (Fig. 2E,F). These results implied that ectopic expression of Dkk1 induces a failure of crypt maintenance by inhibition of proliferation. The patchy loss of crypts probably reflects the previously demonstrated mosaic expression achieved with the fragment of the villin gene used in the transgene construct (Pinto et al. 1999). This could also explain why transgenic animals with locally disorganized intestinal epithelium can still survive to adulthood.

The hallmark of activated canonical Wnt signaling is accumulation of nuclear $\beta$-catenin (Batlle et al. 2002; van de Wetering et al. 2002). As previously described, immunostaining with a $\beta$-catenin antibody revealed mem-
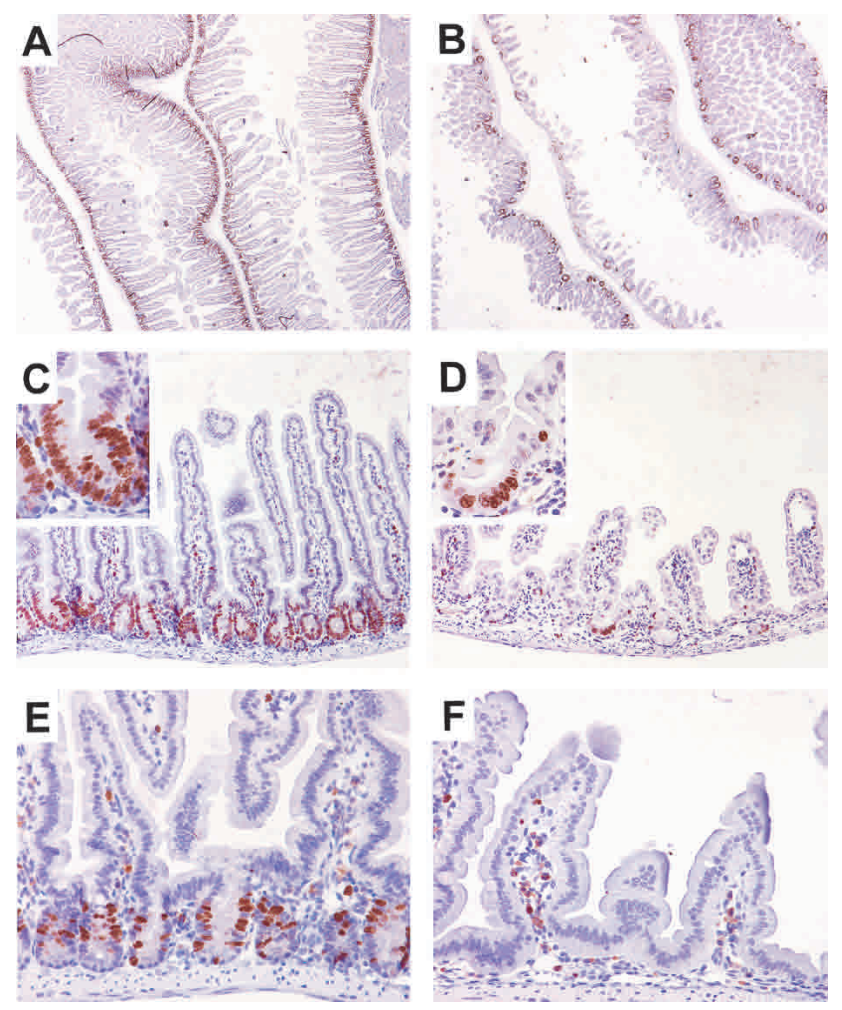

Figure 2. Intestinal cell proliferation is inhibited in Dkk1 transgenic mice. Immunohistochemical analysis of small intestine sections from wild-type $(A, C)$ or transgenic $(B, D)$ adult mice stained with an antibody against proliferating cell antigen Ki-67, and wildtype $(E)$ or transgenic $(F)$ adult mice labeled with $\mathrm{BrdU}$ and stained with an anti-BrdU antibody. Note that proliferative cells are abundantly present in regularly distributed crypts flanking the villi from the wild-type intestine $(C$, inset), but are absent from patchy cryptless areas in the transgenic intestine, persisting only in scarce residual crypts $(D$, inset $)$. Original magnification: $A, B, 2 \times ; C, D, 10 \times$; insets, $60 \times ; E, F, 20 \times$. 
brane-localized $\beta$-catenin along the crypt-villus axis as well as nuclear $\beta$-catenin in cells occupying basal positions of the crypt in sections of wild-type small intestine (Fig. 3A). In contrast, in areas of transgenic sections where crypts were missing, the resulting lining epithelium was devoid of nuclear $\beta$-catenin staining (Fig. 3B). Thus, ectopic expression of Dkk1, indeed, blocked activation of the Wnt pathway, strongly implying that the loss of canonical Wnt signaling is responsible for the observed intestinal phenotype in transgenic mice.

We next asked whether this Dkk1-dependent downregulation of nuclear $\beta$-catenin affected the expression of $\beta$-catenin target genes. We chose Enc-1 as a crypt marker and alkaline phosphatase (AP) as a villus marker (van de Wetering et al. 2002), and examined their expression by immunohistochemistry. In wild-type small intestine sections, Enc-1 immunostaining was restricted to the cytoplasm of crypt epithelial cells, whereas this staining was completely absent from transgenic specimens (Fig. $3 \mathrm{C}, \mathrm{D})$. For AP, in contrast, membrane immunostaining was only visible for villus-associated cells of wild-type animals, whereas both villi and the intervillus epithelium appeared positive in transgenic sections (Fig. 3E,F).
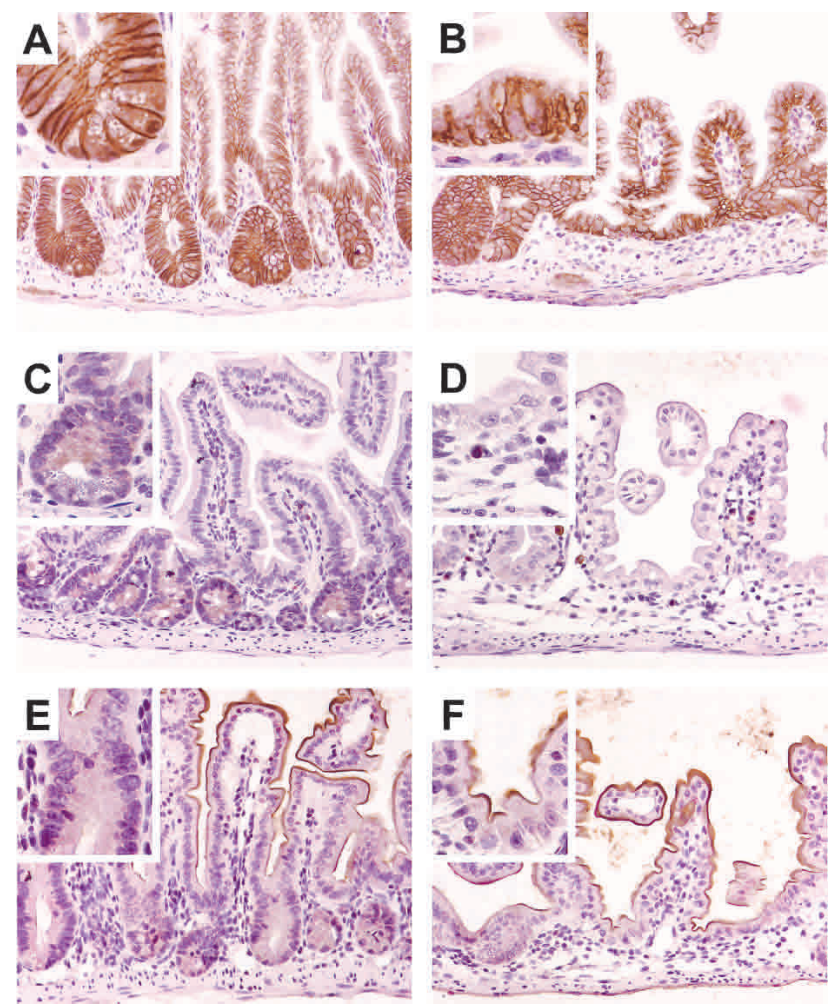

Figure 3. Nuclear $\beta$-catenin and related target genes expression in transgenic intestinal mucosa. Immunohistochemical analysis of small intestine sections from wild-type $(A, C, E)$ and transgenic $(B, D, F)$ adult mice stained with antibodies against $\beta$-catenin $(A, B)$, Enc-1 $(C, D)$, and $\mathrm{AP}(E, F)$. Staining of $\beta$-catenin shows accumulation in the nucleus of cells at the crypt base ( $A$ and inset), but is absent from the nucleus of cells of the lining epithelium in the cryptless regions $(B$ and inset). Staining indicates that Enc-1 cytoplasmic expression restricted to the crypt cells ( $C$ and inset) is completely absent from the intervillus lining epithelium ( $D$ and inset). Staining reveals that AP expression at the apical domain of the villus-associated cells ( $E$ and inset) is found in the cells of the lining epithelium in cryptless areas ( $F$ and inset). Original magnification: $A-F, 20 \times$; insets, $60 \times$.
The same pattern was obtained by immunostaining with another differentiation (villus) marker, FABP-L (liver fatty acid-binding protein; Simon et al. 1993; data not shown). These results showed that the surface epithelium replacing the crypts in Dkk-1 transgenic mice displayed a differentiated phenotype, thus indicating that inhibition of proliferation in presumptive crypt regions by blockade of canonical Wnt signaling promotes terminal differentiation.

The epithelium of the mouse small intestine consists of four principal cell types: absorptive enterocytes, and secretory goblet, enteroendocrine, and Paneth cells (Stappenbeck et al. 1998). Because AP is a differentiation marker for enterocytes, we investigated the status of the three other cell types. All three secretory cell types were absent from affected areas of the small intestine epithelium of transgenic specimens when compared with wildtype specimens, except for some cells in rare residual crypts (Fig. 4A-F). Notably, these data established that the activity of the Wnt $/ \beta$-catenin pathway is required for the emergence of secretory cell types in the epithelium of the small intestine, possibly through regulating the proliferation of a common secretory lineage progenitor. Consistent with this idea and based on the knowledge that this progenitor expresses Math1 (Yang et al. 2001), we performed immunostaining with an anti-Math1 antibody (Helms and Johnson 1998). We confirmed that Math1 was expressed in the nucleus of all three secretory cell types as well as in certain progenitor cells in the midpart of the crypt in wild-type small intestine sections (Fig. 4G). In contrast, no Math1 expression was found in the intestinal epithelium of transgenic animals (Fig. 4H). We tentatively concluded that the Wnt/ $\beta$-catenin pathway is essential for the maintenance of Math1-positive progenitors for the secretory cell lineage. Nonetheless, Math1 itself did not appear to be a direct target gene of Tcf4 in the gut because its expression was maintained within goblet cells of Tcf4-deficient mice (see Supplementary Fig. 3). Intriguingly, although goblet cells were absent from Dkk1 transgenic intestines, their differentiation did not seem to be affected in Tcf4-deficient mice. This suggests that in the fetal gut, an initial wave of goblet cell differentiation may occur independently of Tcf4.

To determine by which molecular mechanism loss of nuclear $\beta$-catenin could affect proliferation in the adult small intestine, we examined the expression of the $\beta$-catenin target gene c-myc and also of the cell cycle inhibitor $\mathrm{p} 21^{\mathrm{CIP} 1 / \mathrm{WAF} 1}$. Our laboratory recently showed that in the nucleus of colorectal cancer cells, the formation of a $\beta$-catenin/Tcf 4 complex results in the direct up-regulation of $\mathrm{c}-m y c$, which, in turn, represses p $21^{\mathrm{CIP} 1 / \mathrm{WAF} 1}$ by direct promoter binding, thereby allowing cells to proliferate (van de Wetering et al. 2002). In wild-type small intestine sections, immunohistochemical detection of c-Myc revealed a nuclear localization restricted to the progenitor cells of the crypts, whereas no expression was observed in affected areas of transgenic sections (Fig. 5A-D). In wild-type animals, p $21^{\mathrm{CIP} 1 / \mathrm{WAF} 1}$ was found mainly in the nuclei of differentiated cells like Paneth cells and villus-associated cells, whereas in transgenic specimens the staining was also detected in the lining epithelium replacing the crypts (Fig. 5E-H). Taken together, these results demonstrated that blocking Wnt-Fz-LRP5/6 interactions leads to repression of $\mathrm{c}-\mathrm{myc}$ expression and induction of 
Pinto et al.

p21 ${ }^{C I P 1 / W A F 1}$ expression. These in vivo findings confirm the proposed role for c-Myc in maintaining intestinal epithelial cells in a proliferative, undifferentiated state, and a role for $\mathrm{p} 21^{\mathrm{CIP1} / \mathrm{WAF} 1}$ as a key mediator of cell cycle arrest and terminal differentiation in the intestinal epithelium.

Homeostasis of the intestinal epithelium is strongly dependent on the balance existing among cell proliferation, cell cycle arrest, cell differentiation, and cell migration (Simon and Gordon 1995). By targeting expression of Dkk1, a potent and specific inhibitor of canonical Wnt signals, we demonstrated that the signaling pathway is active in adult normal intestinal epithelium and is required for the formation of normal crypt-villus units through the regulation of proliferation, cell positioning, and differentiation. Furthermore, we provide in vivo evi-
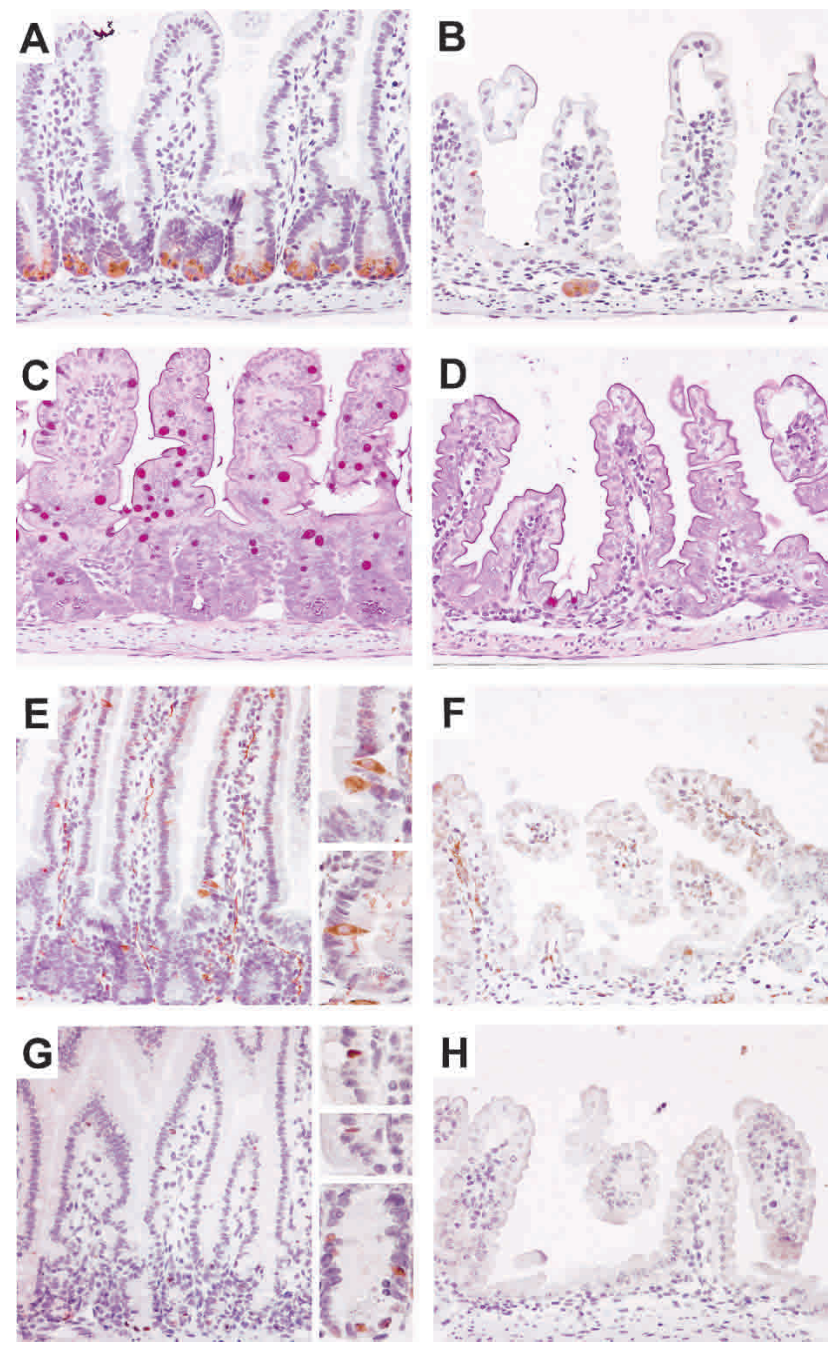

Figure 4. Secretory cell lineage is depleted in Dkk1 transgenic intestinal epithelium. Representative sections of the small intestine from wild-type $(A, C, E, G)$ and transgenic $(B, D, F, H)$ adult animals stained for representation of secretory cell types: anti-lysozyme antibody (Paneth cells; $A, B$ ), periodic acid/Schiff (goblet cells; $C, D$ ), anti-synaptophysin (enteroendocrine cells and nerve fibers; $E, F$ ), and anti-Mathl antibody (all three types and common progenitors; $G, H$ ). Note that all three secretory cell types and their Math1-positive common progenitors $(G$, bottom inset) are absent from cryptless areas of the transgenic epithelium (except in residual crypts). Original magnification: $A-H, 20 \times$; insets, $40 \times$.
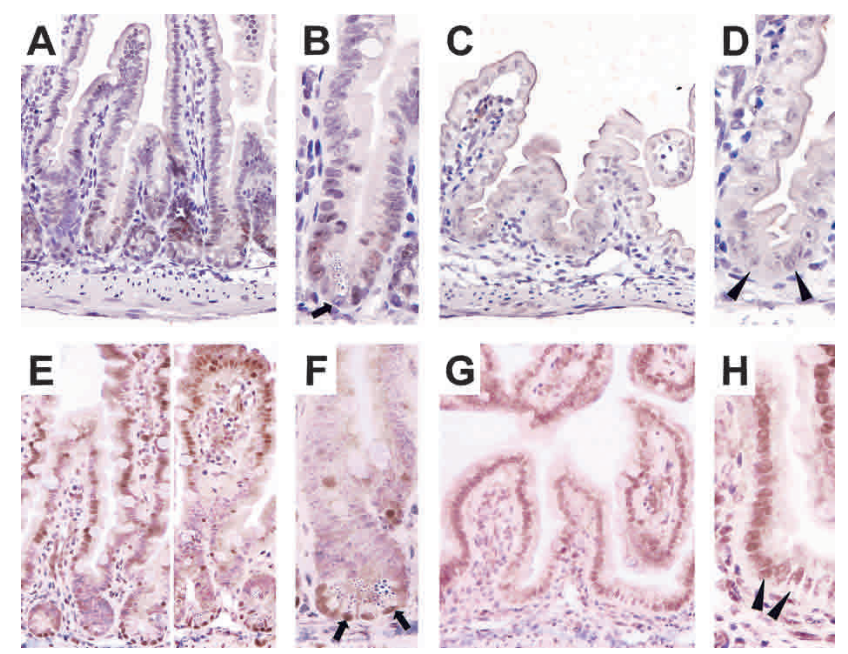

Figure 5. Complementary pattern of expression for c-Myc and $\mathrm{p} 21^{\mathrm{CIP1} / \mathrm{WAF} 1}$ in wild-type and transgenic intestinal epithelium. Representative sections of the small intestine from wild-type $(A, B, E, F)$ and transgenic $(C, D, G, H)$ adult animals stained with an anti-c-myc antibody $(A-D)$ or an anti-p21 $1^{\mathrm{CIP1} / \mathrm{WAF} 1}$ antibody $(E-H)$. The arrows in $B$ and $F$ indicate Paneth cells displaying a reverse nuclear staining for $\mathrm{c}-\mathrm{Myc}$ and $\mathrm{p} 21^{\mathrm{CIP} 1 / \mathrm{WAF} 1}$. The arrowheads in $D$ and $H$ show that p2 $1^{\mathrm{CIP1} / \mathrm{WAF} 1}$ is expressed in the nucleus of the cells lining the intervillus epithelium contrary to c-Myc. Original magnification: $A, C, E, G, 20 \times ; B, D, F, H, 40 \times$.

dence to substantiate the opposing roles of c-Myc and $\mathrm{p} 21^{\mathrm{CIP} 1 / \mathrm{WAF} 1}$ in regulating the proliferation-differentiation switch in the intestinal epithelium, as suggested by previous studies with cultured cells (van de Wetering et al. 2002). An unexpected finding of our work is the apparent increased requirement of secretory cell progenitors for canonical Wnt signaling compared with enterocyte progenitors. In conclusion, our studies attest to the critical importance of canonical Wnt signals in the homeostasis of the intestinal epithelium.

\section{Materials and methods}

\section{Expression vector}

The villin-Dkk1 transgenic expression construct was generated by cloning the murine Dkk1 ORF sequence (a kind gift from C. Niehrs, DKFZ, Heidelberg, Germany) at the initiation codon of the 9-kb regulatory region of the mouse villin gene (Pinto et al. 1999) using standard techniques. An SV40 termination and polyadenylation cassette was added downstream.

\section{Generation of Villin-Dkk1 mice}

Villin-Dkk1 transgenic mice were generated by microinjection of linearized plasmid into the pronuclei of fertilized eggs of B6CBAF1/JIco mice. Transgenic mice were identified by Southern blotting and PCR analysis using tail genomic DNA. Founder mice were bred to C57BL/6 wild-type mice to produce $\mathrm{F}_{1}$ hemizygous mice, and the littermates were bred to generate $\mathrm{F}_{2}$ homozygous mice. All mice were maintained at the Central Laboratory Animal Institute (Utrecht, The Netherlands) according to institutional guidelines.

\section{Reverse transcription-PCR analysis}

Total RNA was isolated with Trizol reagent (Life Technologies), and reverse transcription and PCR experiments were processed as described (Pinto et al. 1999). For the transgene amplification, 5'-CAACTTCCTAA GATCTCC-3' sense primer and 5'-GATCAGAACTGAGTTCAAGG-3' antisense primer were used, generating a 176-bp product.

Histology, immunohistochemistry, BrdU labeling, and in situ hybridization

Tissues were fixed in $10 \%$ formalin or $4 \%$ paraformaldehyde, paraffinembedded, and sectioned at 3-6 $\mu \mathrm{m}$ for hematoxylin/eosin staining or 
immunostaining procedure as described (Batlle et al. 2002). The primary antibodies used were rabbit anti-lysozyme (1:500; DAKO), goat antiEphB3 (1:50; R\&D Systems), mouse anti-Ki67 (1:100; Novocastra), mouse anti-BrdU (1:500; Becton Dickinson), mouse anti- $\beta$-catenin (1:50; Transduction Laboratories), mouse anti-Enc1 (1:100; Pharmingen), rabbit antialkaline phosphatase (1:400; BioTrend), rabbit anti-synaptophysin (1:100; DAKO), rabbit anti-Math1 (1:50; a kind gift from J. Johnson, University of Texas Southwestern Medical Center, Dallas, TX; Helms and Johnson 1998), rabbit anti-c-myc (1:500; Upstate Biotechnology), and rabbit antip21 $1^{\mathrm{CIP} 1 / \mathrm{WAF} 1}$ (1:500; Pharmingen). The peroxidase-conjugated secondary antibodies used were Mouse or Rabbit EnVision+ (DAKO). For BrdU labeling, mice were injected with $100 \mu \mathrm{g}$ of BrdU (Sigma) per gram of body weight and killed after $2 \mathrm{~h}$. For in situ hybridization, Dkk1 antisense riboprobe was synthesized from the mouse cDNA (a kind gift from C. Niehrs, DKFZ, Heidelberg, Germany), and the procedure was performed as described (Moorman et al. 2001).

\section{Acknowledgments}

We thank C. Niehrs for Dkk1 cDNA; J. Johnson for Math1 antibody; A. Zine for Mathl immunostaining protocol; Clevers laboratory members for technical assistance and helpful discussions; Rachel Giles for histological insight; and A. Hurlstone for valuable comments on the manuscript.

The publication costs of this article were defrayed in part by payment of page charges. This article must therefore be hereby marked "advertisement" in accordance with 18 USC section 1734 solely to indicate this fact.

\section{References}

Andl, T., Reddy, S.T., Gaddapara, T., and Millar, S.E. 2002. WNT signals are required for the initiation of hair follicle development. Dev. Cell 2: $643-653$.

Bafico, A., Liu, G., Yaniv, A., Gazit, A., and Aaronson, S.A. 2001. Novel mechanism of Wnt signalling inhibition mediated by Dickkopf-1 interaction with LRP6/Arrow. Nat. Cell Biol. 3: 683-686.

Batlle, E., Henderson, J.T., Beghtel, H., van den Born, M.M., Sancho, E., Huls, G., Meeldijk, J., Robertson, J., van de Wetering, M., Pawson, T., et al. 2002. $\beta$-Catenin and TCF mediate cell positioning in the intestinal epithelium by controlling the expression of EphB/ephrinB. Cell 111: 251-263.

Bienz, M. and Clevers, H. 2000. Linking colorectal cancer to Wnt signaling. Cell 103: 311-320.

Booth, C., Brady, G., and Potten, C.S. 2002. Crowd control in the crypt. Nat. Med. 8: 1360-1361.

Fodde, R., Edelmann, W., Yang, K., van Leeuwen, C., Carlson, C., Renault, B., Breukel, C., Alt, E., Lipkin, M., Khan, P.M., et al. 1994. A targeted chain-termination mutation in the mouse Apc gene results in multiple intestinal tumors. Proc. Natl. Acad. Sci. 91: 8969-8973.

Fodde, R., Smits, R., and Clevers, H. 2001. APC, signal transduction and genetic instability in colorectal cancer. Nat. Rev. Cancer 1: 55-67.

Gordon, J.I. and Hermiston, M.L. 1994. Differentiation and self-renewal in the mouse gastrointestinal epithelium. Curr. Opin. Cell Biol. 6: 795-803.

Helms, A.W. and Johnson, J.E. 1998. Progenitors of dorsal commissural interneurons are defined by MATH1 expression. Development 125: 919-928.

Janssen, K.P., El Marjou, F., Pinto, D., Sastre, X., Rouillard, D., Fouquet, C., Soussi, T., Louvard, D., and Robine, S. 2002. Targeted expression of oncogenic K-ras in intestinal epithelium causes spontaneous tumorigenesis in mice. Gastroenterology 123: 492-504.

Kinzler, K.W. and Vogelstein, B. 1996. Lessons from hereditary colorectal cancer. Cell 87: 159-170.

Korinek, V., Barker, N., Moerer, P., van Donselaar, E., Huls, G., Peters, P.J., and Clevers, H. 1998. Depletion of epithelial stem-cell compartments in the small intestine of mice lacking Tcf-4. Nat. Genet. 19: 379-383.

Mao, B., Wu, W., Li, Y., Hoppe, D., Stannek, P., Glinka, A., and Niehrs, C. 2001. LDL-receptor-related protein 6 is a receptor for Dickkopf proteins. Nature 411: 321-325.

Moorman, A.F., Houweling, A.C., de Boer, P.A., and Christoffels, V.M. 2001. Sensitive nonradioactive detection of mRNA in tissue sections: Novel application of the whole-mount in situ hybridization protocol.
J. Histochem. Cytochem. 49: 1-8.

Moser, A.R., Pitot, H.C., and Dove, W.F. 1990. A dominant mutation that predisposes to multiple intestinal neoplasia in the mouse. Science 247: 322-324.

Oshima, M., Oshima, H., Kitagawa, K., Kobayashi, M., Itakura, C., and Taketo, M. 1995. Loss of Apc heterozygosity and abnormal tissue building in nascent intestinal polyps in mice carrying a truncated Apc gene. Proc. Nat1. Acad. Sci. 92: 4482-4486.

Pinto, D., Robine, S., Jaisser, F., El Marjou, F., and Louvard, D. 1999. Regulatory sequences of the mouse villin gene that efficiently drive transgenic expression in immature and differentiated epithelial cells of small and large intestines. J. Biol. Chem. 274: 6476-6482.

Powell, S.M., Zilz, N., Beazer-Barclay, Y., Bryan, T.M., Hamilton, S.R., Thibodeau, S.N., Vogelstein, B., and Kinzler, K.W. 1992. APC mutations occur early during colorectal tumorigenesis. Nature 359: 235237.

Schluter, C., Duchrow, M., Wohlenberg, C., Becker, M.H., Key, G., Flad, H.D., and Gerdes, J. 1993. The cell proliferation-associated antigen of antibody Ki-67: A very large, ubiquitous nuclear protein with numerous repeated elements, representing a new kind of cell cycle-maintaining proteins. J. Cell Biol. 123: 513-522.

Semenov, M.V., Tamai, K., Brott, B.K., Kuhl, M., Sokol, S., and He, X. 2001. Head inducer Dickkopf-1 is a ligand for Wnt coreceptor LRP6. Curr. Biol. 11: 951-961.

Shibata, H., Toyama, K., Shioya, H., Ito, M., Hirota, M., Hasegawa, S. Matsumoto, H., Takano, H., Akiyama, T., Toyoshima, K., et al. 1997. Rapid colorectal adenoma formation initiated by conditional targeting of the Apc gene. Science 278: 120-123.

Simon, T.C. and Gordon, J.I. 1995. Intestinal epithelial cell differentiation: New insights from mice, flies and nematodes. Curr. Opin. Genet. Dev. 5: 577-586.

Simon, T.C., Roth, K.A., and Gordon, J.I. 1993. Use of transgenic mice to map cis-acting elements in the liver fatty acid-binding protein gene (Fabpl) that regulate its cell lineage-specific, differentiation-dependent, and spatial patterns of expression in the gut epithelium and in the liver acinus. J. Biol. Chem. 268: 18345-18358.

Stappenbeck, T.S., Wong, M.H., Saam, J.R., Mysorekar, I.U., and Gordon, J.I. 1998. Notes from some crypt watchers: Regulation of renewal in the mouse intestinal epithelium. Curr. Opin. Cell Biol. 10: 702-709.

Tamai, K., Semenov, M., Kato, Y., Spokony, R., Liu, C., Katsuyama, Y., Hess, F., Saint-Jeannet, J.P., and He, X. 2000. LDL-receptor-related proteins in Wnt signal transduction. Nature 407: 530-535.

van de Wetering, M., Sancho, E., Verweij, C., de Lau, W., Oving, I., Hurlstone, A., van der Horn, K., Batlle, E., Coudreuse, D., Haramis, A.P., et al. 2002. The $\beta$-catenin/TCF-4 complex imposes a crypt progenitor phenotype on colorectal cancer cells. Cell 111: 241-250.

Yang, Q., Bermingham, N.A., Finegold, M.J., and Zoghbi, H.Y. 2001. Requirement of Math1 for secretory cell lineage commitment in the mouse intestine. Science 294: 2155-2158.

Zorn, A.M. 2001. Wnt signalling: Antagonistic Dickkopfs. Curr. Biol. 11: R592-R595. 


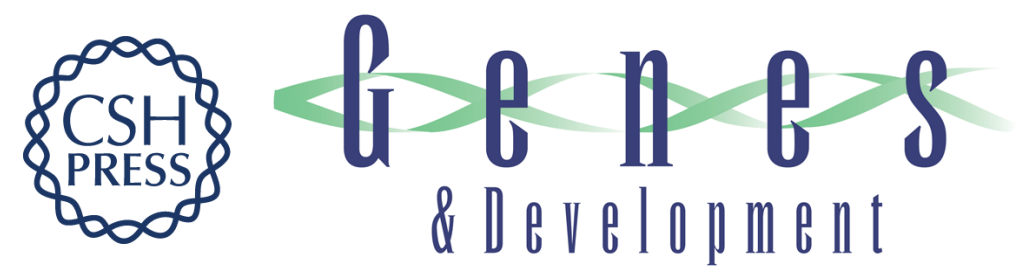

\section{Canonical Wnt signals are essential for homeostasis of the intestinal epithelium}

Daniel Pinto, Alex Gregorieff, Harry Begthel, et al.

Genes Dev. 2003, 17:

Access the most recent version at doi:10.1101/gad.267103

\section{Supplemental http://genesdev.cshlp.org/content/suppl/2003/06/30/17.14.1709.DC1 Material}

References This article cites 28 articles, 9 of which can be accessed free at: http://genesdev.cshlp.org/content/17/14/1709.full.html\#ref-list-1

\section{License}

Email Alerting

Receive free email alerts when new articles cite this article - sign up in the box at the top Service

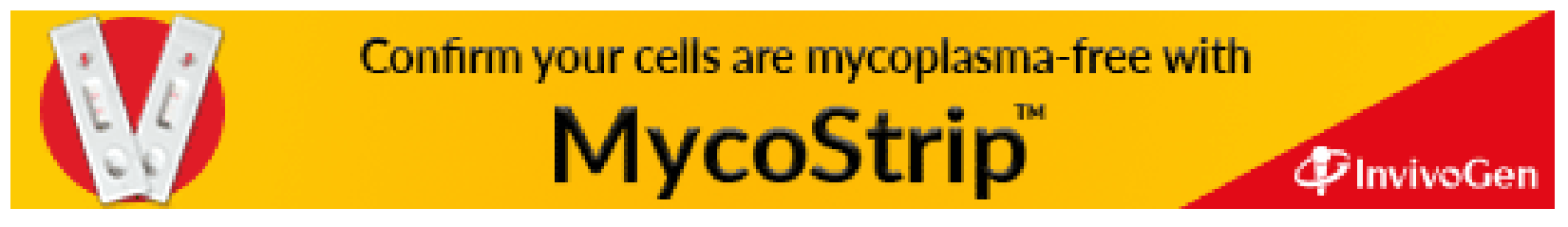

